\title{
Pengembangan Media Pop-Up Book Batik Lasem untuk Sekolah Dasar
}

\author{
Hehen Julianto ${ }^{1 *}$, Achmad Hilal Madjdi ${ }^{2}$, Mohammad Kanzunnudin ${ }^{3}$ iD \\ 1,2,3 Universitas Muria Kudus, Kudus, Indonesia \\ *Corresponding author: hehenj87@gmail.com
}

\begin{abstract}
Abstrak
Kurangnya media pembelajaran pada muatan seni budaya, menyebabkan minat belajar siswa menjadi rendah. Tujuan dari penelitian ini adalah untuk mengetahui kelayakan media pop-up book batik Lasem untuk kelas V sekolah dasar. Metode penelitian ini mengacu pada teori Borg dan Gall, dengan menggunakan tujuh langkah pelaksanaan penelitian yakni penelitian dan pengumpulan informasi, perencanaan penelitian, mengembangkan produk awal, validasi desain produk, revisi desain produk, uji coba produk, dan revisi hasil uji produk. Teknik pengumpulan data yang digunakan adalah teknik observasi, wawancara, dan angket. Analisis yang digunakan dalam penelitian ini adalah analisis kuantitatif dan kualitatif meliputi observasi pembelajaran dan validasi produk media pembelajaran. Sumber data pada penelitian ini adalah siswa dan guru kelas V sekolah dasar. Hasil analisis dari proses validasi ahli materi memperoleh jumlah skor 44 persentase $88 \%$ dengan kategori sangat baik. Validasi ahli media memperoleh jumlah skor 68 persentase $91 \%$ dengan kategori sangat baik. Berdasarkan hasil validasi maka media pop-up book batik Lasem untuk sekolah dasar dinyatakan layak untuk digunakan dalam proses pembelajaran. Implikasi media ini diharapkan dapat membantu siswa untuk belajar secara mandiri.
\end{abstract}

Kata kunci: Media pembelajaran, pop-up book, batik Lasem.

\section{Abstract}

The lack of learning media on cultural arts content causes students' interest in learning to be low. The purpose of this study was to determine the feasibility of Lasem batik pop-up book media for fifth grade elementary school. This research method refers to the theory of Borg and Gall, using seven steps of research implementation, namely research and information gathering, research planning, developing initial products, product design validation, product design revisions, product trials, and product test results revisions. Data collection techniques used are observation, interviews, and questionnaires. The analysis used in this research is quantitative and qualitative analysis including learning observation and validation of learning media products. Sources of data in this study were students and teachers of grade V elementary school. The results of the analysis of the material expert validation process obtained a total score of 44 percentages of $88 \%$ with a very good category. The media expert validation obtained a total score of 68,91\% in the very good category. Based on the validation results, the Lasem batik pop-up book media for elementary schools was declared feasible to be used in the learning process. The implication of this media is expected to help students to learn independently.

Keywords: Media, multiplication, math, low grade stud

\begin{tabular}{|c|c|c|}
\hline History: & & Publisher: Undiksha Press \\
\hline Received & : 30 Desember 2020 & Licensed: This work is licensed under \\
\hline Revised & : 16 Januari 2021 & a Creative Commons Attribution 4.0 License \\
\hline Accepted & : 17 April 2021 & (c) (†) () \\
\hline Published & : 25 Juli 2021 & $\underbrace{}_{\mathrm{EY}} \mathrm{SA}_{\mathrm{SA}}$ \\
\hline
\end{tabular}

\section{Pendahuluan}

Pendidikan sebagai proses pembelajaran memiliki komponen-komponen yang saling berkaitan. Melalui pendidikan seorang dapat mengembangkan pengetahuan kognitif, afektif dan psikomotorik (Khanifah et al., 2012; Wisnu Budi Wijaya, 2019). Pada kurikulum 2013 untuk Sekolah Dasar terdapat muatan pelajaran Seni Budaya dan Prakarya. Mareza (2017:35) menyatakan Pendidikan Seni Budaya dan Prakarya diberikan pada siswa sekolah dasar agar tetap menumbuhkan rasa kecintaan siswa terhadap seni budaya Indonesia. Menurut PP No. 19 tahun 2005 tentang Standar Nasional Pendidikan menyebutkan bahwa pendidikan seni budaya meliputi berbagai aspek kehidupan. Kompetensi dasar muatan lokal yang berkenaan 
dengan seni, budaya, dan keterampilan diintegrasikan ke dalam mata pelajaran Seni Budaya dan Prakarya. Pendidikan seni budaya memposisikan siswa sebagai pewaris budaya bangsa yang kreatif sekaligus memiliki kecerdasan intelektual. Pendidikan seni budaya ditujukan untuk menjembatani antara kebutuhan keluarga dan masyarakat serta disesuaikan dengan tujuan pendidikan nasional. Selain itu, dapat memberikan wawasan di sekitar peserta didik dan memberikan peluang untuk mengembangkan kemampuan dirinya yang dianggap perlu oleh daerah yang bersangkutan.

Permasalahan saat ini terjadi, pendidikan seni budaya kurang diminati oleh peserta didik. Hal ini disebabkan materi yang terdapat di dalam buku paket kurang terkait dan terasa asing bagi siswa. Terutama pada muatan pelajaran Seni Budaya dan Prakarya (SBdP) materi karya seni rupa daerah. Alangkah baiknya jika mengangkat materi seni rupa daerah Kabupaten Rembang, yaitu batik Lasem. Selain memperkaya pengetahuan siswa, hal ini juga mengajarkan mereka untuk mencintai budaya daerah mereka sendiri. Berdasarkan hasil observasi di kelas V SDN 2 Pulo saat pembelajaran berlangsung. Guru sedang mengajarkan Tema 3 Sub Tema 3 Pembelajaran 2 yang di dalamnya terdapat muatan pelajaran SBdP (Seni Budaya dan Prakarya) yaitu KD 3.4 memahami karya seni rupa daerah. Dari hasil observasi diketahui bahwa pembelajaran belum menggunakan media yang menarik. Guru hanya memanfaatkan buku paket siswa dan papan tulis. Hal ini memicu siswa kurang minat untuk mengikuti pembelajaran, terutama saat membaca pesan atau materi yang ditulis guru. Siswa juga terlihat kurang fokus dalam mengikuti pembelajaran. Beberapa siswa terlihat ramai dan sibuk bermain sendiri. Pada akhir pembelajaran, guru melakukan evaluasi pembelajaran. Hasil evaluasi sangat mengecewakan karena banyak siswa yang memperoleh nilai di bawah Kriteria Ketuntasan Minimum (KKM). Seharusnya guru menggunakan media pembelajaran yang menarik sehingga dapat meningkatkan motivasi dan minat belajar siswa. Media pembelajaran dapat membuat siswa berpikir dan menganalisis materi pembelajaran yang diberikan oleh guru dengan baik. Situsi belajar akan menjadi menyenangkan dan siswa dapat memahami materi dengan mudah. (Nurrita, 2018:171).

Berdasarkan pemaparan permasalahan mengenai pembelajaran Seni Budaya dan Prakarya (SBdP), perlu untuk mengembangkan media pembelajaran yang menarik dan sekaligus mengangkat materi karya seni rupa daerah Kabupaten Rembang. Media merupakan suatu wadah yang digunakan narasumber untuk pengiriman isi pesan yang ingin diteruskan kepada orang yang disampaikan atau sang penerima pesan untuk menciptakan proses pembelajaran (Mustofa \& Syafi'ah, 2018; Sutrisno \& Siswanto, 2016)(Andriyani \& Suniasih, 2021; Hanik, 2020; Indahini et al., 2018). Melalui penggunaan media, penyampaian materi pembelajaran dapat diseragamkan, proses pembelajaran berjalan lebih menarik, siswa lebih interaktif, waktu pembelajaran berjalan lebih efisien dan meningkatkan kualitas pembelajaran (Kuswanto et al., 2017; Melianti et al., 2020). Media dapat memberikan kejelasan objek atau materi yang di pelajari sehingga menarik perhatian siswa (Habibi \& Setyaningtyas, 2021; Mustofa \& Syafi'ah, 2018)(Citra \& Rosy, 2020; Pratiwi et al., 2018) . Pemanfaatan media dalam pembelajaran bisa membantu keterbatasan guru ketika memberikan informasi maupun keterbatasan waktu pelajaran di kelas (Indahini et al., 2018; Yektyastuti \& Ikhsan, 2016).

Media pembelajaran yang dikembangkan yaitu media pop-up book batik Lasem. Media pop-up book batik Lasem merupakan sebuah buku pop-up yang di dalamnya berisikan materi tentang batik Lasem. Dengan adanya media pop-up book ini diharapkan dapat meningkatkan motivasi dan minat belajar siswa dalam pembelajaran serta membantu siswa dalam memahami materi tentang karya seni rupa daerah (Habibi \& Setyaningtyas, 2021; Mustofa \& Syafi'ah, 2018). Pop-up sangat mengagumkan jika digunakan pada kegiatan pembelajaran berbentuk visual (Karisma et al., 2020; Mustika, 2020). Media visual dapat memberi visualisasi cerita yang sangat menarik, karena gambar disajikan dapat bergerak pada setiap bagian yang dibuka maupun digeser, serta tampilannya yang berbentuk dua atau tiga 
dimensi (Ahmadi et al., 2017; Hanim et al., 2016). Batik Lasem memiliki keunikan yang khas sebagai wujud kebudayaan lokal Lasem yang telah dimaknai dan berlangsung selama bertahun-tahun (Farid, 2012). Beberapa temuan tersebut menyatakan media pop up book layak diterapkan pada proses pembelajaran. namun, belum ada yang mengembangkan media ini pada muatan seni budaya khususnya pada materi batik lasem. Penelitian ini bertujuan untuk mengembangkan media pop up book batik lasem untuk sekolah dasar. Adanya media ini dapat membantu siswa dalam mempelajari tentang batik lasem.

\section{Metode}

Jenis Dalam penelitian ini digunakan desain penelitian dan pengembangan dengan tujuh langkah pelaksanaan mengacu pada teori Borg dan Gall. 7 langkah dalam penelitian tersebut yakni (1) pengumpulan informasi, (2) perencanaan penelitian, (3) mengembangkan desain produk awal, (4) validasi desain produk, (5) revisi desain produk, (6) uji coba produk, (7) revisi hasil uji produk. 1) Tahap pengumpulan informasi dilakukan dengan melakukan analisis kebutuhan, analisis kurikulum, analisis karakteristik siswa, dan analisis media yang baik. Analisis kurikulum dilakukan dengan menganalisis Kompetensi Inti (KI), Kompetensi Dasar (KD), dan indikator pencapaian kompetensi yang terdapat pada buku siswa sehingga nantinya dapat digunakan sebagai acuan dalam mengembangkan media pop-up book. Analisis kebutuhan dilakukan untuk mengetahui kebutuhan yang diperlukan oleh guru dan siswa dalam proses pembelajaran khususnya tentang batik lasem. Analisis karakteristik siswa meliputi melakukan analisis terhadap peserta didik yang akan menggunakan media yang dikembangkan. Analisis media yang baik digunakan untuk mengetahui karakteristik media yang baik. 2) Tahap perencanaan dilakukan perancangan media pembelajaran pop-up book yang dimulai dari menentukan materi yang akan dikembangkan dalam media pop-up book, membuat rancangan pop-up book. kemudian dikonsultasikan dengan dosen pembimbing untuk mendapatkan masukan atau saran agar bisa dilakukan perbaikan. 3) Tahap pengembangan dilakukan pengembangan media pop-up book yang telah dikonsultasikan dengan dosen pembimbing. Setelah dilakukan validasi desain produk dilakukan penilaian oleh 2 orang dosen dan 2 orang guru. Selanjutnya dilaksanakan revisi desain produk dan uji coba produk serta revisi produk. Instrumen pengumpulan data pada penelitian ini adalah angket, pedoman wawancara, dan pedoman observasi. Analisis validasi tersebut menggunakan skala tipe ratting scale. Validator memberikan skor pada item pernyataan. Skor jawaban tersebut meliputi kategori sebagai berikut : (5) sangat baik, (4) baik, (3) cukup baik, (2) kurang baik, (1) sangat kurang baik.

\section{Hasil dan Pembahasan Hasil Penelitian}

Penelitian ini dilaksanakan untuk mengembangkan media pop-up book batik lasem untuk sekolah dasar. Hasil penelitian ini adalah media pop-up book yang sudah valid. Hasil tersebut diperoleh melalui tahap pengumpulan informasi, perancangan pengembangan, serta validasi produk oleh dosen dan guru. Tahap informasi diperoleh bahwa guru setuju jika dalam pembelajaran batik lasem menggunakan media pop up book. Kompetensi Inti (KI), Kompetensi Dasar (KD), serta indikator pencapaian kompetensi yang digunakan sebagai acuan dalam mengembangkan media. Analisis karakteristik siswa digunakan untuk mengetahui karakteristik siswa yang akan menggunakan media. Analisis media yang baik digunakan untuk menganalisis kriteria media yang baik untuk SD. Adapun media pop-up book yang dikembangkan mengacu pada 6 aspek yang meliputi: (1) kriteria aspek sampul meliputi identitas dan kemenarikan sampul (2) aspek format meliputi warna, tulisan, huruf, 
dan tata letak; (3) kriteria aspek isi meliputi kecocokan materi dengan indikator, kemampuan media menjelaskan materi, kelengkapan materi, dan daya tarik materi pada media; (4) kriteria aspek bahasa meliputi penggunaan bahasa, kebakuan bahasa, dan keefektifan kalimat; (5) kriteria aspek praktis berkaitan dengan penggunaan media; dan (6) kriteria aspek efektif juga berkaitan dengan penggunaan media (Karisma et al., 2020).

Pada tahap perancangan dilakukan perancangan media yang akan dikembangkan. Rancangan media menggunakan aplikasi Photoshop CS5. Rancangan media kemudian dikonsultasikan dengan dosen pembimbing untuk mendapatkan masukan dan saran. Setelah disetujui oleh dosen pembimbing kemudian dilanjutkan ke tahap pengembangan. Tahap pengembangan dilakukan dengan mulai mengembangkan media sesuai dengan rancangan yang telah disetujui oleh dosen pembimbing. Media dikembangkan dengan sampul yang menarik, dilengkapi petunjuk penggunaan media, KD dan indikator pencapaian kompetensi, Setelah media selesai dikembangkan tahap selanjutnya adalah melakukan uji coba media untuk mengetahui validitas media yang dikembangkan. Validasi ahli dilakukan untuk memberikan penilaian kevalidan terhadap media dan memperoleh saran dari validator serta untuk proses revisi produk media.

Validasi ahli untuk produk media dilakukan oleh ahli materi dan ahli media. Validasi produk oleh ahli materi terbagi menjadi 3 aspek yaitu aspek materi (terdapat 4 butir indikator), aspek bahasa (terdapat 2 butir indikator), dan aspek pembelajaran (terdapat 4 butir indikator). Sedangkan validasi produk oleh ahli media terbagi menjadi 2 aspek yaitu aspek kemenarikan fisik (terdapat 3 butir indikator) dan aspek tampilan (terdapat 7 butir indikator). Adapun hasil validasi dapat dilihat dalam Tabel 1 dan Tabel 2.

Tabel 1. Data Hasil Validasi Produk oleh Ahli Materi

\begin{tabular}{clcc}
\hline No & Indikator Penilaian & Butir Penilaian & Skor \\
\hline 1 & Aspek materi & 4 item & 18 \\
2 & Aspek bahasa & 2 item & 8 \\
3 & Aspek pembelajaran & 4 item & 18 \\
Jumlah & 10 item & 44 \\
Persentase & & $88 \%$ \\
Kategori & Sangat Baik \\
\hline
\end{tabular}

Tabel 2. Data Hasil Validasi Produk oleh Ahli Media

\begin{tabular}{clcc}
\hline No & Indikator Penilaian & Butir Penilaian & Skor \\
\hline 1 & Aspek kemenarikan fisik & 3 item & 13 \\
2 & Aspek tampilan & 12 item & 55 \\
Jumlah & 15 item & 68 \\
$\begin{array}{l}\text { Persentase } \\
\text { Kategori }\end{array}$ & Sangat Baik \\
\hline
\end{tabular}

Berdasarkan Tabel 1 dan Tabel 2 dapat diketahui bahwa hasil validasi ahli materi dan ahli media dalam pengembangan media pop-up book batik Lasem untuk sekolah dasar berturut-turut memperoleh jumlah skor 44 persentase $88 \%$ dengan kategori sangat baik dan jumlah skor 68 persentase $91 \%$ dengan kategori sangat baik pula. Dalam proses validasi peneliti mendapat beberapa saran. Saran dari ahli digunakan untuk melakukan proses revisi produk sehingga revisi produk tidak dilakukan secara menyeluruh melainkan hanya sesuai dengan saran validator saja. Adapun saran validator yaitu media pop-up book perlu ditambahkan bagian pendahuluan yaitu prakata, datar isi, KI, KD, dan indikator. Halaman 
sampul perlu ditambahkan contoh gambar batik lasem. dan Penambahan contoh motif batik yang ada di pengrajin batik Lasem.

Berdasarkan pada hasil analisis validitas media pop-up book yang menunjukkan bahwa media pop-up book yang dikembangkan berkualifikasi "sangat baik". Hal ini menunjukkan bahwa media pop-up book batik lasem layak digunakan sebagai media pembelajaran bagi siswa sekolah dasar. Hal ini sejalan dengan teori perkembangan kognitif Piaget yang menyatakan bahwa anak usia sekolah dasar memerlukan objek yang bersifat konkret dalam pembelajaran (Ibda, 2015). Hal ini dapat difasilitasi dengan menggunakan media pop-up book yang telah dikembangkan. Pop-up book merupakan media pembelajaran tiga dimensi berbentuk buku yang memuat gambar timbul ketika dibuka (Eva, 2002; Mustika \& Ain, 2020). Media pop-up book memiliki keunggulan dibandingkan media cetak lainnya. Adapun keunggulan media pop-up book dibandingkan dengan media cetak lainnya yaitu: (1) pop-up book dibuat menggunakan kertas yang tebal sehigga tidak mudah rusak, (2) setiap bagian pop-up book berisi halaman dengan gambar yang menarik, (3) membuat siswa lebih aktif dan antusias dalam belajar, (4) pop-up book bisa digunakan secara individu ataupun dalam kelompok (Afrianti Yulia \& Wirman, 2020; Mustofa \& Syafi'ah, 2018).

Sedangkan, ditinjau dari aspek sajian media pop-up book dapat dibuka dan ditutup tanpa merusak atau merobek lembaran kertas yang lain, kertas lembaran pop-up book tidak berpotongan sehingga tidak ada halangan saat membuka atau menutup setiap halaman pada media, pop-up book rapi saat tertutup, pop-up book memiliki unsur bentuk, warna, dan tekstur yang menarik, dan pop-up book tidak mudah rusak (Habibi \& Setyaningtyas, 2021; Sari \& Kusmariyatni, 2020). Disamping itu, kelebihan media pop-up book ini, yaitu: (1) membantu guru dalam menyampaikan materi batik lasem pada siswa sekolah dasar. (2) membuat pembelajaran menjadi lebih menarik dan dapat mengefisienkan waktu dan tenaga; (3) meningkatkan minat dan motivasi siswa untuk belajar, karena dengan penggunaan media ini siswa mendapatkan pengalaman belajar baru sehingga berdampak kemampuannya, (4) mampu meningkatkan keterlibatan siswa saat proses pembelajaran, sehingga pengetahuan yang didapat lebih dipahamai dan tahan lama.

Temuan penelitian sebelumnya menyatakan Pop-up sangat mengagumkan jika digunakan pada kegiatan pembelajaran berbentuk visual (Karisma et al., 2020; Mustika, 2020). Media visual dapat memberi visualisasi cerita yang sangat menarik, karena gambar disajikan dapat bergerak pada setiap bagian yang dibuka maupun digeser, serta tampilannya yang berbentuk dua atau tiga dimensi (Ahmadi et al., 2017; Hanim et al., 2016). Batik Lasem memiliki keunikan yang khas sebagai wujud kebudayaan lokal Lasem yang telah dimaknai dan berlangsung selama bertahun-tahun (Farid, 2012). Beberapa temuan penelitian sebelumnya yang menyatakan media pop up book ini layak digunakan pada proses pembelajaran.

\section{Simpulan}

Berdasarkan hasil validasi produk maka media pop-up book batik Lasem untuk sekolah dasar yang peneliti kembangkan layak digunakan sebagai media pembelajaran untuk siswa kelas V sekolah dasar muatan pelajaran Seni Budaya dan Prakarya (SBdP) materi karya seni rupa daerah. Keterbatasan dalam penelitian ini yaitu hanya dilakukan pada tahap validasi, media ini belum diimplementasikan, maka direkomendasikan penelitian selanjutnya dapat mengembangkan penelitian ini melalui eksperimen. Implementasi penelitian ini diharapkan dapat membantu siswa dalam belajar secara mandiri dan menarik minat siswa dalam mendalami kebudayaan khususnya batik lasem. 


\section{Daftar Rujukan}

Afrianti Yulia, A., \& Wirman. (2020). Penggunaan Media Busy Book Untuk Menstmulasi Kemampuan Membaca Anak. Jurnal Pendidikan Tambusai, 4(2), 1156-1163.

Ahmadi, F., Sutaryono, Witanto, Y., \& Ratnaningrum, I. (2017). Pengembangan Media Edukasi "Multimedia Indonesian Culture" (Mic) Sebagai Penguatan Pendidikan Karakter Siswa Sekolah Dasar. Jurnal Penelitian Pendidikan, 34(2), 127-136. https://doi.org/10.15294/jpp.v34i2.12368.

Andriyani, N. L., \& Suniasih, N. W. (2021). Development Of Learning Videos Based On Problem-Solving Characteristics Of Animals And Their Habitats Contain in Science Subjects On 6th-Grade. Journal of Education, 5(1), 37-47. https://doi.org/http://dx.doi.org/10.23887/jet.v5i1.32314.

Citra, C. A., \& Rosy, B. (2020). Keefektifan Penggunaan Media Pembelajaran Berbasis Game Edukasi Quizizz Terhadap Hasil Belajar Teknologi Perkantoran Siswa Kelas X SMK Ketintang Surabaya. Jurnal Pendidikan Administrasi Perkantoran (JPAP), 8, 261-272.

Eva, novita. (2002). Pengembangan Media Pembelajaran Pop-Up Book Tema Lingkungan Dan Alam Sekitar Untuk Siswa Kelas IV SD Di Kabupaten Blitar Nourma. In jurnal pgsd (Vol. 1, Issue 2). https://doi.org/g.

Farid, M. N. (2012). Peranan Muatan Lokal Materi Batik Tulis Lasem Sebagai Bentuk Pelestarian Budaya Lokal. Komunitas. International Journal of Indonesian Society and Culture, 4(1). https://doi.org/10.15294/komunitas.v4i1.2400.

Habibi, C. D., \& Setyaningtyas, E. W. (2021). Pengembangan Media Pop-Up Book untuk Kemampuan Pemecahan Masalah pada Pembelajaran Bangun Ruang Kubus dan Balok Kelas V SD. Jurnal Pendidikan Matematika, 05(02), 1341-1351. https://doi.org/10.31004/cendekia.v5i2.620.

Hanik, E. U. (2020). Self directed learning berbasis literasi digital pada masa pandemi covid19 di Madrasah Ibtidaiyah. ELEMENTARY: Islamic Teacher Journal, 8(1), 183. https://doi.org/10.21043/elementary.v8i1.7417.

Hanim, F., Sumarmi, \& Amirudin, A. (2016). Pengaruh Penggunaan Multimedia Pembelajaran Interaktif Penginderaan Jauh Terhadap Hasil Belajar Geografi. Jurnal Pendidikan: Teori, Penelitian, Dan Pengembangan, Vol.1(4), 752-757. https://doi.org/10.17977/jp.v1i4.6246.

Ibda, F. (2015). Perkembangan Kognitif: Teori Jean Piaget. Intelektualita, 3(1), 242904.

Indahini, R. S., Sulton, \& Husna, A. (2018). Pengembangan Multimedia Mobile Learning Pada Mata Pelajaran Simulasi Dan Komunikasi Digita Kelas X SMK. Jurnal Kajian Teknologi Pendidikan, 1(2), 141-148. http://journal2.um.ac.id/index.php/jktp/article/view/3730.

Karisma, I. K. E., Margunayasa, I. G., \& Prasasti, P. A. T. (2020). Media Pop-Up Book pada Topik Perkembangbiakan Tumbuhan dan Hewan Kelas VI Sekolah Dasar. Jurnal Ilmiah Sekolah Dasar, 4(2), 121-130. https://doi.org/10.23887/jisd.v4i2.24458.

Khanifah, S., Pukan, K. K., \& Sukaesih, S. (2012). Pemanfaatan Lingkungan Sekolah Sebagai Sumber Belajar Untuk Meningkatkan Hasil Belajar Siswa. Journal of Biology Education, 1(1), 66-73. https://doi.org/10.15294/jbe.v1i1.379.

Kuswanto, J., Walusfa, Y., Artikel, S., Korespondensi, A., Ratu Penghulu No, J., Sari, K., Baru, T., Raja Tim, B., Ogan Komering Ulu, K., \& Selatan, S. (2017). Pengembangan Multimedia Pembelajaran pada Mata Pelajaran Teknologi Informasi dan Komunikasi Kelas VIII. Innovative Journal of Curriculum and Educational Technology IJCET, 6(2), 58-64.

Melianti, E., Risdianto, E., \& Swistoro, E. (2020). Pengembangan Media Pembelajaran 
Berbasis Multimedia Interaktif Menggunakan Macromedia Director Pada Materi Usaha Dan Energi Kelas X. Jurnal Kumparan Fisika, 3(1), 1-10. https://doi.org/10.33369/jkf.3.1.1-10.

Mustika, D. (2020). Peningkatan Kreativitas Mahasiswa Menggunakan Model Project Based Learning dalam Pembuatan Media IPA Berbentuk Pop Up Book. Jurnal Basicedu, 4(4), 1167-1175. https://doi.org/10.31004/basicedu.v4i4.518.

Mustika, D., \& Ain, S. Q. (2020). Peningkatan Kreativitas Mahasiswa Menggunakan Model Project Based Learning dalam Pembuatan Media IPA Berbentuk Pop Up Book. Jurnal Basicedu, 4(4), 1167-1175. https://doi.org/https://doi.org/10.31004/basicedu.v4i4.518.

Mustofa, R., \& Syafi'ah, R. (2018). Pengembangan Media Pembelajaran Pop Up Book Materi Kenampakan Permukaan Bumi Mata Pelajaran IPA Kelas III SD. ELSE (Elementary School Education Journal), 2, 30-41. https://doi.org/http://dx.doi.org/10.30651/else.v2i2.1723.

Pratiwi, N. P. E. Y., Pudjawan, K., \& Sukmana, A. I. W. I. Y. (2018). Pengembangan Multimedia Pembelajaran Interaktif Berbasis Proyek pada Mata Peajaran Bahasa Indonesia pada siswa Kelas V. Edutech Universitas Pendidikan Ganesha, 6, 123-133. https://doi.org/10.23887/jeu.v6i1.20277.

Sari, D. V., \& Kusmariyatni, N. (2020). The Validity of the Pop-Up Book Media on Puberty Topics for Sixth Grade Elementary School. Indonesia Journal Of Elementary Education, 4(2), 179-186. https://doi.org/10.23887/ijee.v4i2.25295.

Sutrisno, V. L. P., \& Siswanto, B. T. (2016). Faktor-Faktor Yang Mempengaruhi Hasil Belajar Siswa Pada Pembelajaran Praktik Kelistrikan Otomotif Smk Di Kota $\begin{array}{llll}\text { Yogyakarta. Jurnal Pendidikan } & \text { Vokasi, } & 6(1), & 111 .\end{array}$ https://doi.org/10.21831/jpv.v6i1.8118.

Wisnu Budi Wijaya, I. K. (2019). Menanamkan Konsep Catur Paramita Pada Anak Usia Dini Di Lingkungan Keluarga Dan Sekolah. Pratama Widya: Jurnal Pendidikan Anak Usia Dini, 3(2), 41-46. https://doi.org/10.25078/pw.v3i2.737.

Yektyastuti, R., \& Ikhsan, J. (2016). Pengembangan Media Pembelajaran Berbasis Android pada Materi Kelarutan untuk Meningkatkan Performa Akademik Peserta Didik SMA. Jurnal Inovasi Pendidikan IPA, 2(1), 88-99. https://doi.org/10.21831/jipi.v2i1.10289. 